\title{
التفسير العلمي وضوابطه عند المفسرين
}

د. علاء حسين خلف

جامعة واسط /كلية التربية
د. ثائر محمود عبيد

الجامعة العراقية

بسم الهه الرحمن الرحيم

\section{المقدمة}

الحمد لله رب العالمين ، وصلاة وسلاماً دائمين على الرحمة المهداة ، سيدنا محمد (صلى اله عليه

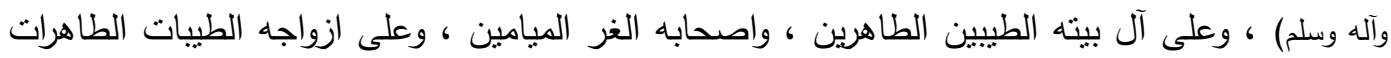

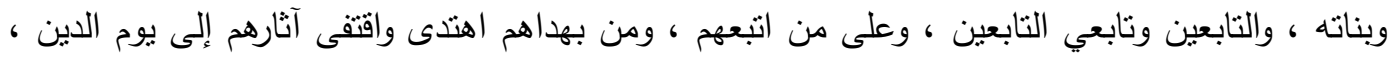

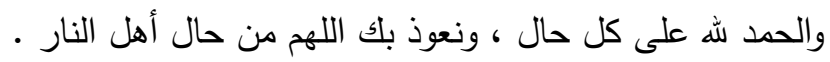
وبعد ...

فان أول ما اعملت فيه القرائح ، وصرفت إليه الهمم العالية ، وصدقت فيه العزائم ، وسار

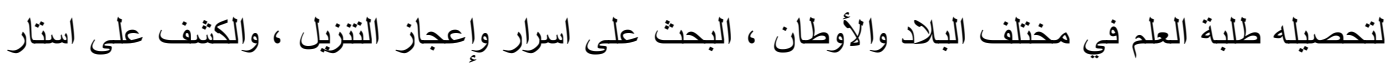

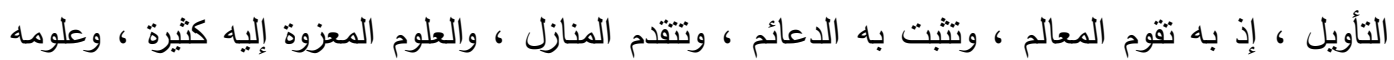

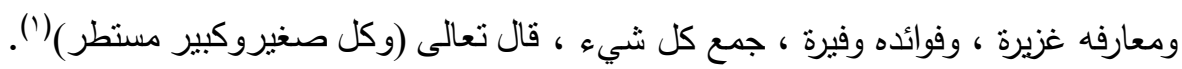
وهدى من الغواية والضال إلى الرشاد والكمال ، ورحمة في الدنيا والاخرة ، وبشرى في ظلمة القبور ، وامان ولطف في البعث والنشور ، قال تعالى (ونزلنا عليك الكتاب تبيانا لكل شيء و هدى ولئ وبشرى

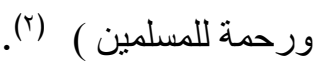
فالامر يتعلق بكتاب الهه العزيز ، قراءةً وفهماً ، وتطبيقاً وتدبراً وعملاً بقوله تعالى :( افلا يتدبرون

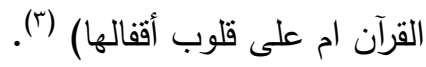


ولا يتّم ذلك إلّا بهمم الرجال العالية ، والنيات المخلصة ، فبرز الرجال الاعلام ، والعقول الافهام

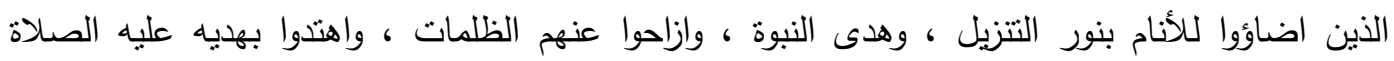

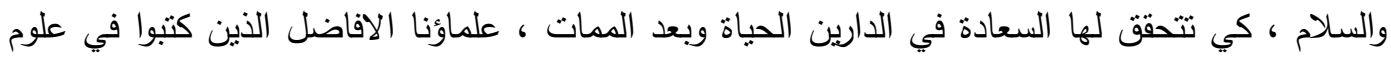

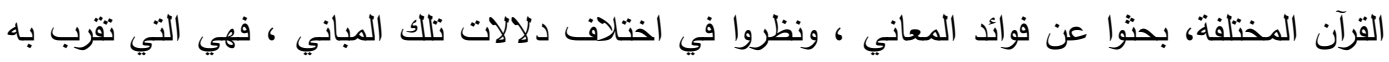

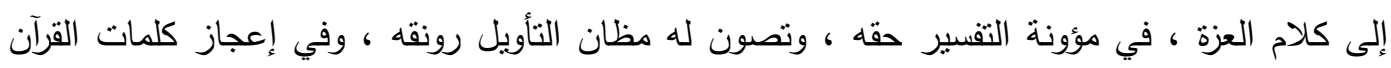

ولذا كانت رحلتنا شاقة وممتعة ، فقد استعنا في كتابة الموضوع ودراسته بعدد من المصادر والمراجع التي أُلفت في الإعجاز القرآني والتفسير العلمي . وقد احتوى هذا البحث على مقدمة وثلاثة مباحث وخاتمة : المبحث الاول : فقد نتاولنا فيه التفسير العلمي والإعجاز العلمي والعلاقة والفرق بينهما . المطلب الاول : تعريف التقسير العلمي • المطلب الثاني : تعريف المعزة لغةً واصطلاحاً . إما المبحث الثاني : ادلة الدجوزين والمانعين للتفسير العلمي وادلتهم ، وقسمته إلى مطلبين : المطلب الاول : اهم العلماء المجيزين للتفسير العلمي وادلتهم . المطلب الثاني : أهم العلماء المانعون للتفسير العلمي وادلتهم . المبحث الثالث : ضوابط التفسير العلمي · وختاماً ... لعلّنا قدّمنا جهداً متواضعاً خدمة لكتاب اله ، وحسبنا في ذلك خالص نيتتا ، وصدق عملنا ، فإن وفقنا فالحمد لله رب العالمين ، وإن اخطأنا ، فلنستغفر اله العظيم ، وصلٌ اللهم على سيدنا محمد وآله وصحبه اجمعين. 


\section{المطلب الاول: التفسير العلمي :}

قبل أن نبدأ بتعريف التقسير العلمي لا بدّ أن نعرف التفسير في لغة وإصطلاحاً التقسير في اللغة : هو الإيضاح والتبيين ومنه قوله تعالى (ولا يأتونك بمنل إلا جئناك بالحق

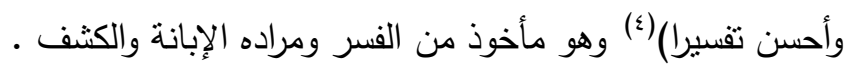

قال إبن منظور (0) : " الفسر : البيان ، وفسّر الثيء يفسره .. ثم قال الفسر : كثف المغطى ، والتفسير :

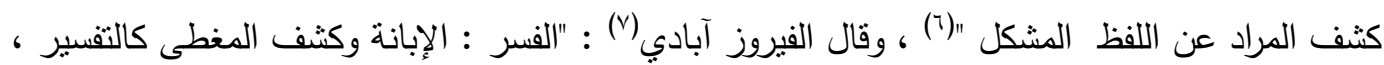

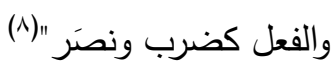

إما التفسير في الإصطلاح فقد عرفه العلماء بتعريفات عديدة بمكن ان ترجع كلها لمعنى واحد ،

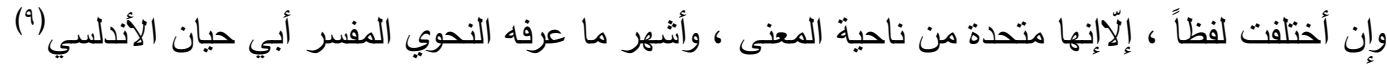

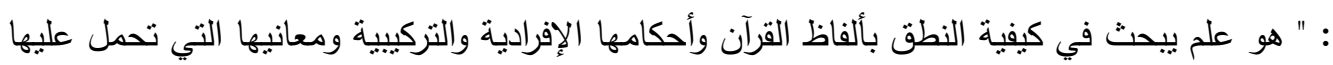

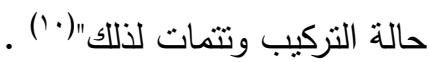

إما التفسير العلمي : ونريد به : "هو التفسير الذي يحكم الاصطلاحات العلمية على عبارات القرآن

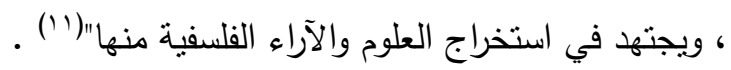

وقد ظهر حديثاً مدلول آخر لهذا العلم نلتمس جوانبه بوصفهم لهذا القرن ، أو العصر ، بانه عصر العلم ( النهضة والنطور ) ، الخ ل....

والذي يهمنا بوصفه ( عصر العلم ) وقد يقصد العلماء والفلاسفة بهذا العلم هو العلم الطبيعي القائم في دراسة ما في الكون من كائنات وعناصر ومواد ، لها خصائصها الذانية وانظمتها التي تحكم من لوناه

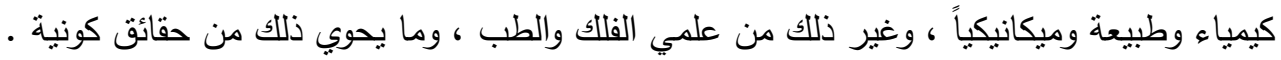
وان العمل بإطار هذا المفهوم للعلم هو التطبيق العلمي عملياً من خلال استعمال الاجهزة والادوات الحديثة في المختبرات والمراصد والتجارب العلمية والاستتباطات المنطقية وغيرها . وهذا ما قصدوه من وصف هذا العصر بــ(العصر العلمي) ، وهو ما تعارف عندهم بالتفسير 


\section{المطلب الثاني : الإعجاز في القرآن الحكيم :}

الفرع الاول : تعريف المعززة لغة :

المعجزة لغة : "نقيض الحزم ، مأخوذ من العز ، وهو عدم القدرة على فعل الثـيء"(rا") .

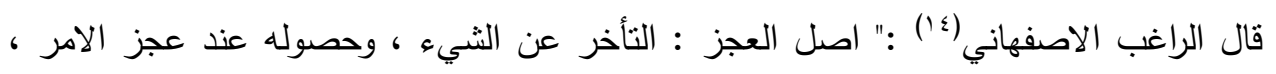

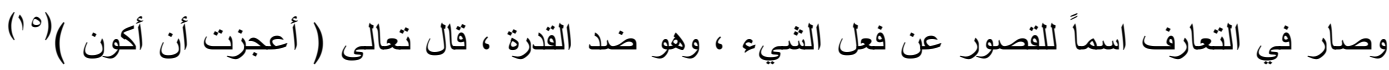
واعجزت فلاناً وعجزته ، وعاجزته : جعلته عاجزاً"(17 ).

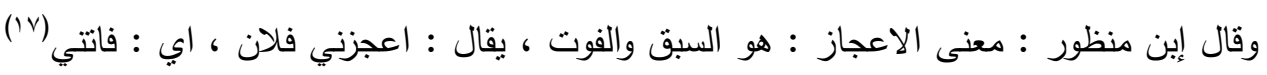

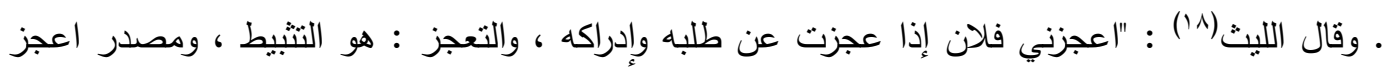

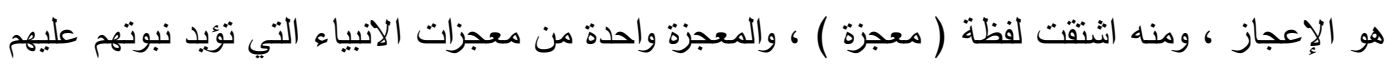
السلام ، وقيل إثبات العجز المغير"(19) (19) وقال الفيروز آبادي : "المعجزة التي يمنع ما اعجز به الخصم عند التحدي"(·r) .

\section{الفرع الثاني : تعريف المعجزة اصطلاحاً}

المعجزة اصطلاحاً :هو امر خارق للعادة يظهره الله تعالى على بد مدعي النبوة تصديقاً له في

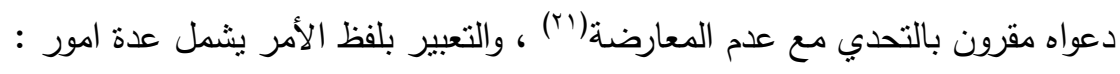
أ- الفعل : كأنشقاق القمر ، ونبع الماء. ب- الترك : كعدم إحراق النار لسيدنا ابراهيم (عليه السلام) •

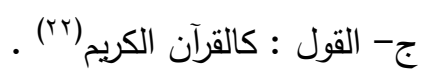

وقد توسع البعض في تعريف المعزة بقولهم : ( بقصد التوضيح ) امر كل أنواع المعزات

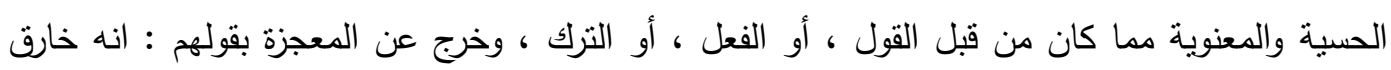

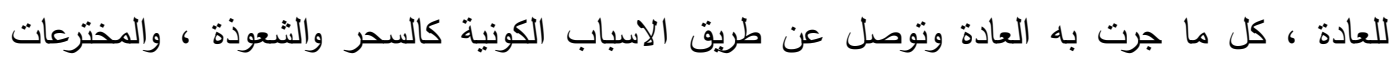

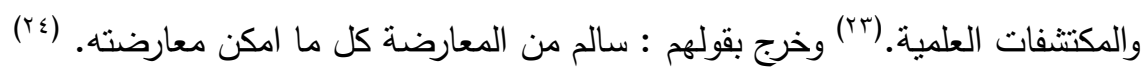


والإتيان بمثله من المظاهر غير المعتادة التي توصل اليها بضرب من التمرين والرياضة .

وقيل : امر ممكن عقلاً خارق للعادة يجريه الله تعالى على يد من اراد أن يؤيده ليثبت بذلك صدق

نبوته وصحة رسالته. (ro)

وهناك فرق بين التفسير العلمي ، والإعجاز العلمي :

اما اولهما : فهو موضوع بحثنا ودراستتا .

وإما الثاني : فأعتبره امراً محتوماً ، لا مجادلة به ولا اشكال ، ذلك ان القرآن انزل قبل اربعة عثر قرناً من الزمن ، وأستعرض الكثير من مظاهر هذا الوجود منها ما يتعلق بالكون ، كخلق السموات والارض وخلق الانسان ، وإنزال المطر والغيث والسحاب، ومجرى الثمس والقمر ، وتكلم عن الكواكب والنجوم واطوار الأجنة والنباتات والبحار ، فإن هذا بحد ذاته يعتبر معجزة علمية للقرآن عن ان القرآن الكريم، ولن يصادم حقيقة هذه النتيجة المتولدة علمباً ، لم أزر العلماء من انكرها ، لا في القدم ولا في العصر الحديث ، وكل ما يثار من ضجة وما يسطر في الصحف ما هو إلّاعن طريق التفسير العلمي لا عن الإعجاز العلمي (rT)

فالإعجاز العلمي أساس رصين وقف عليه المسلمين جميعاً ، لكن قسم من العلماء قالوا : ما زال الإعجاز العلمي متحققاً في القرآن وثابتاً ، فما علينا إلّأن نطبقه في جميع الآيات ، وبين الحقائق العلمية

إذن المسلمون جميعهم قالوا : بالاعجاز العلمي للقرآن ، ولكنهم مختلفون في تفسيره علمياً(YV) . 


\section{المطلب الاول : أدلة المجوزين للتفسير العلمي :}

ومن اهم العلماء المجيزين للتفسير العلمي ، هم :

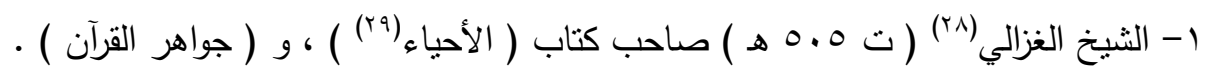

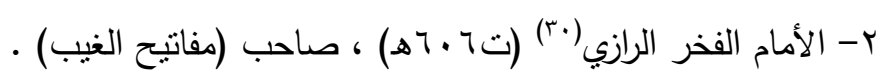

r- طنطاوي جوهري(') ، صاحب كتاب ( الجواهر في تفسير القرآن ).(r") وفي عصرنا هذا نجد الثيخ محمد عبدة ، وتلميذه الثيخ محمد رشبد رضا، وكذلك الثيخ عبد الحمبد بن باديس ، ومحمد أبو زهرة ، محدث المغرب ، والثيخ الثنقيطي (r؟r).

وللمجيزين لهذا النوع من التفسير العلمي ادلة نذكر منها ما يلي :

ا- إنّ هذا الاتجاه اراد أن يلفت نظر المسلمين إلى العلوم المختلفة كي يستفيدوا منها في بناء

حضارتهم الجديدة. (ع) إن)

ץ- الاغتباط الحاصل لاى المسلمين بسبب التوافق الناشئ بين الحقائق العلمية ، وبين اخلا ما

ندين به وهو القرآن الكريم •

r- الرد على مخططات الغزو الفكري على الاسلام ؛ بإثبات ان القرآن لا يخالف العلم الصحيح

، ولا يتعارض مع الحقائق الثابتة التي لا تتغير •

ع- لقد ثبت أن القرآن الكريم اثار مجملاً ومفصلاً في آيات عدة إلى مجموعة من الحقائق

العلمية المقررة التي لا تقبل الجدل على إعجازه السماوي ، فمثلاً عن ( نشأة الجنين في بطن الأم خلقاً بعد

خلق في ظلمات ثلاث ) ، وهو ما اكده العلم الحديث. (ro) 


\section{المطلب الثاني : المانعون للتفسير العلمي وادلتهم}

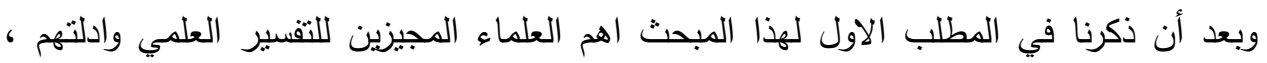
نذكر هنا العلماء المانعين وادلتهم ، واهم العلماء المانعين لهذا النوع من التقسير ، وهم :

$$
\text { 1- الامام الثاطبي(זr) : صاحب كتاب ( الموافقات في اصول الفقه) }
$$

ץ- محمد مصطفى المراغي( (rv) : صاحب كتاب (بحث في ترجمة القرآن الى اللغات الأجنبية) فضلاً عن وجود علماء في عصرنا الحاضر ، عارضوا هذا النوع من التفسير ، منهم الثيخ

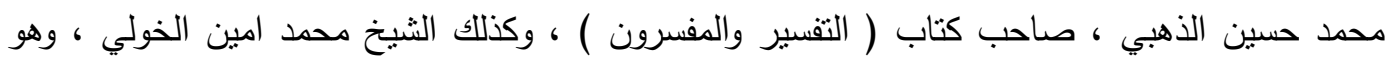

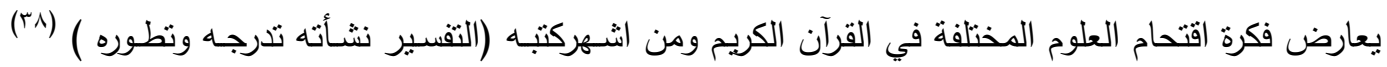

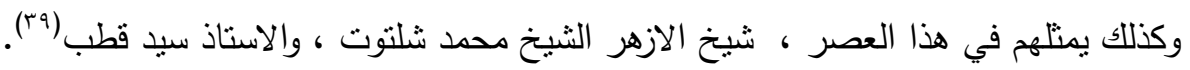
ومن اهم ادلة المانعين لهذا النوع : 1- إنّ مهمة القرآن الكريم دينية اعتقادية . ץ- يجب أن نقف بعبارات القرآن الكريم عندما فهمه العرب الخلص ، ولا تتجاوز ما الفوه من علومهر

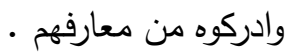

r- إنّ الفهم الدقيق للألفاظ يحتم علينا فههها في حدود الاستعمال الذي نزلت فيه ، وهذا يحول بيننا وبين

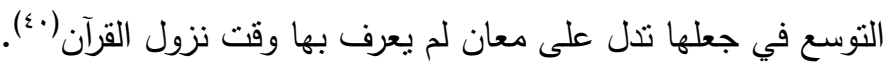
ع - إنّ اله تعالى لم ينزل القرآن ليكون كتاباً يحدث للناس عن نظريات العلوم ودقائق الفنون • 0- التفسير العلمي يعرض الناس للدوران مع مسائل العلوم المختلفة في كل زمان ومكان والعلوم لا تعرف

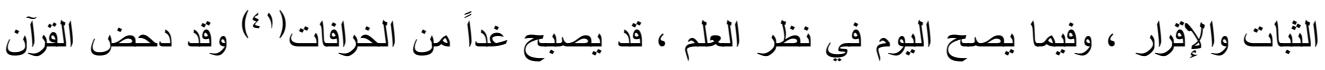
الكريم بردّ هذه الثبهات عبر السنين . 


\section{المبحث الثالث}

\section{ضوابط التفسير العلمي}

اهم الضوابط التي وضعها انصار التفسير العلمي ، والتي ينبغي أن يحكمها المفسرون في

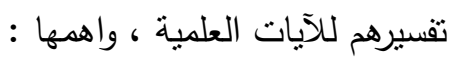

1- المعرفة التامة والثابتة من أن القرآن الكريم كتاب هداية ، لا كتاب علم.(r؟) r- استتباط القضايا ، إما من صريح النص ، أو من الثارات قوية واضحة(r؟؛).

ץ- يجب على المفسر أن لا يخالف القواعد النحوية الواضحة المقررة في التفاسير ، وان لا يجعل الحقيقة

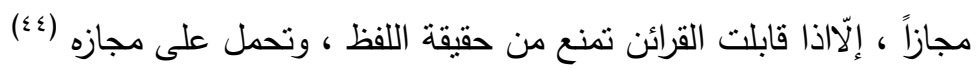
ع - لا يجوز تحميل الآيات الكونية فوق ما تحتمل ، والخروج منها عن المنىى المتفق مع السياق العام الذي وردت فيه الآية .

ه- يجب أن يفسر القرآن بالحقائق العلمية الواضحة والثابتة والابتعاد عن الفروض والنظريات ؛ لأن الحقائق هي السبيل عن الحق في التغيير ، وإما النظريات هي عرضة للتصحيح والتعديل . ؟- لا بذّ من جمع جميع الآيات الواردة في الموضوع المبحوث عنه ، حتى تسنطيع أن ينوصل إلى الحقيقة الثابنة.

V - ان القرآن العظيم ليس كتاباً لعلوم الدنيا فحسب ، بمعنى أنه ليس كتاباً فلكياً ، ولا كتاباً طبياً ، ولا كتاباً

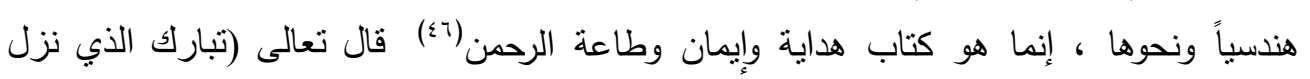

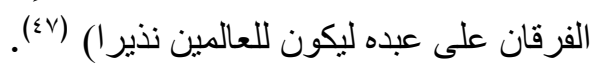

1- أن يقرر إن هذا حسب فهم النص ، ولا يلزمه من ذلك ان هذه حقيقة النص ؛ لان نصوص القرآن من

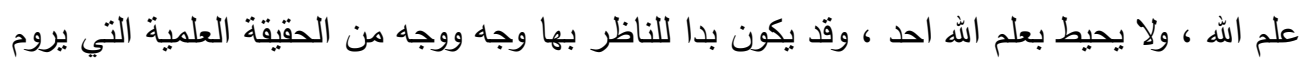

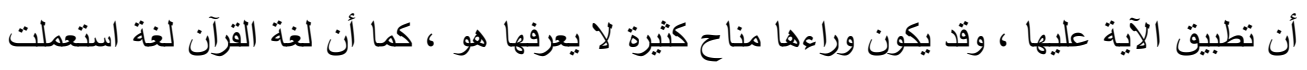




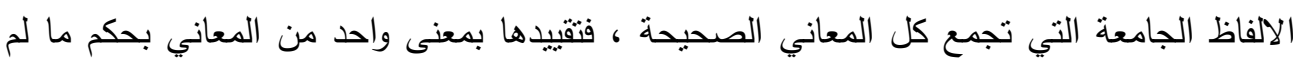

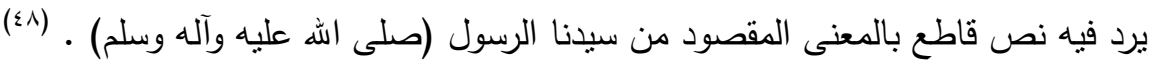

9- الابتعاد عن التكلف بتحميل الآيات ما لا تحتمله حرصاً على إرجاعها لاكتشاف علمي.(9)

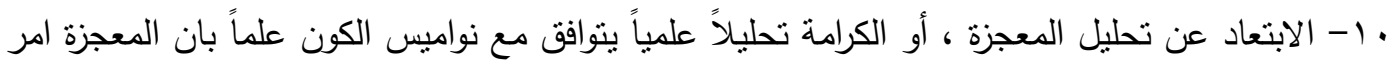
خارق للعادة ، بمعنى انها لا تخضع لقوانين الحياة ، ومن ذللك : قميص نبي الله يوسف(عليه السلام) ، وارتداد بصر النبي يعقوب (عليه السلام) ، قيل : لأن القميص كان فيه اثر عرق وان فئ في لهاه

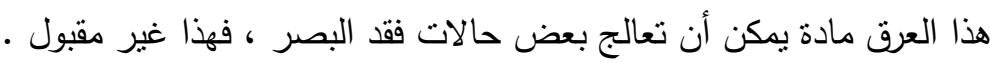
1ا-لا يجوز الخوض في هذا الباب دون معرفة بقواعد التقسير واصوله الامر الذي يؤدي إلى وقوع الخطأ والقصور في الفهم. (ن) r ا - لا يمكن تعليل الخوارق ، أو الغيبيات تعليلاً مادياً علمياً ، وربما ساعد العلم في تقريب بعض الامور

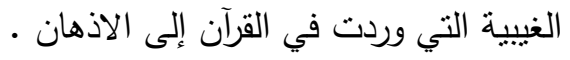

با - لا يصح أن نجعل القرآن تبعاً ، والعلم التجريبي اصلاً وحكماً.(0) ع ا- إذا وقع تعارض بين الدلالة النصية المقطوع بها وبين أحدى النظريات العلمية ترفض هذه النظرية ؛

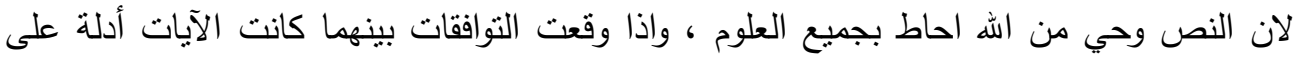

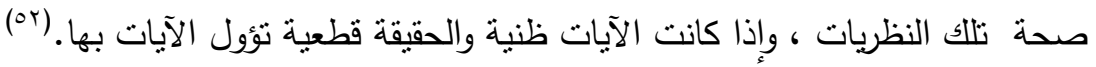
10 - لا يعني التفسير العلمي أن نفند ما فسره المنقدمون من معان وإستتباطات لا مخالفة فيها للحقائق

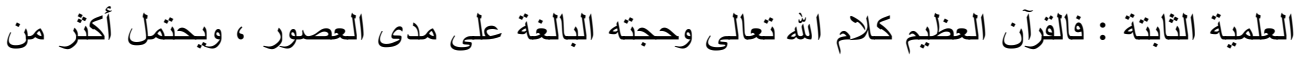
وجه ، وقد فهم كل مفسر بمقدار ثقافة عصره ومجتمعه ، وما تبيّن له من فهم وأدراك ، ثم جاء العلم الحديث فكثف عن وجوه ومعاني لم يدركها السابقون ، وكلما تقدم العلم التجريبي كلما تجّلت لنا وجوه جديدة من وجوه الاعجاز العلمي • 17 ا إن لا نطغى المباحث التي تتعلق بالتفسير العلمي للقرآن الكريم عن المقصود الاول من القرآن الكريم ،

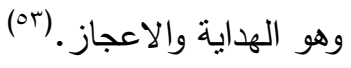


V ا أن تكون هذه الابحاث دافعاً كبيراً للمسلمين الى نهضتهم ، وتلفتهم إلى جلالة القرآن المعجز ، وتحركهم للأنتفاع بقوى هذا الكون الكبير - الذي سخره الله لنا - انتفاعاً يعيد أمة الاسلام لمجدها .

1 ا - أن تكون هذه الابحاث دافعاً للمسلم من اجل نرسيخ عقيدته وشعوره بالانتماء لهذا الدين الاسلامي •

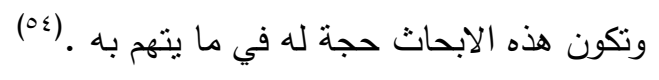

9 ا - أن لا تكون هذه الابحاث هي التفسير العلمي النهائي على هذا النص بحيث لا يحتمل غيره ، بل يجب ان بذكر لتوسيع دائرة دلالته ، وبستشهد بها على ذلك الوجه بحيث لا يؤثز على بطلان تلك هل

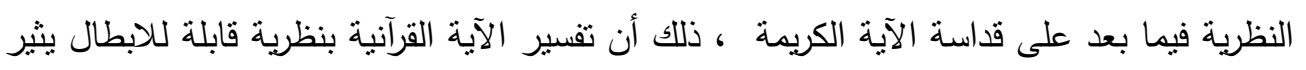
شكوكاً حول الحقائق القرآنية في اذهان المسلمين ، كلما تعرضت نظرية للرد ، أو البطلان.(00) • ץ- ضرورة أنحصار التفسير العلمي بما تدل عليه لغة القرآن العربية وفيه لا بدّ من: أ- مراعاة معاني مفردات اللغة ابان نزول الوحي . ب- مراعاة أسس النحو العربية ومدلولاتها . ج- مراعاة أسس البلاغة العربية ومدلولاتها ـ (7ه) 


\section{الخاتمة}

بعد أن وفقنا الله تعالى لإكمال هذا البحث ، وبعد العرض الموجز ، لا بدّ لنا ان نشير إلى بعض النتائج التي توصلنا اليها على شكل نقاط :

ا- لا يمكن القبول بالتفسير العلمي بشكل مطلق ، ولا رفضه بشكل كامل ، وإنما نقبل التفسير العلمي ما

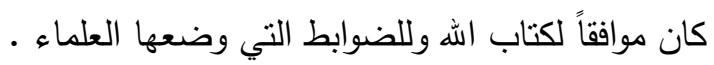

ץ- التعرف على موقف العلماء وعلاقة التقسير بالاعجاز العلمي ، ومن العلماء الذي ايده واخذ به ، ومنهم من رفضه واسنتكره مع ذكر أدلتهم .

ب- إن التفسير العلمي للقرآن مرفوض إذا اعتمد على النظريات العلمية التي لم تثبت، ولم تصل إلى درجة الحقيقة العلمية ، فلا يفسر القرآن بالنظريات ، وإنما يفسر بالحقائق التي اثتتها العلم باليقين •

ع- إن التفسير العلمي مرفوض إذا خرج بالقرآن عن لغته العربية ، فهي اللغة التي نزل بها. ه- إن العلم الحديث الذي جاء عبر الوف السنين إذا ثبت عدم صحة ما ذكره القرآن، ضاعت قضية الإيمان به ، ولكن القائل والفاعل هو الله تعالى .

ج- إن التفير العلمي للقرآن مقبول ممن رزقه اله علماً بالقرآن ، وعلماً بالسنن الكونية ، لا كل من هب ودب ، فكتاب الله اعظم من ذلك .

V- إن التقسير العلمي مقبول إذا التزم المفسر القواعد المعروفة في اصول التقسير ^- التفسير العلمي يختلف عن الاعجاز ، وهذا ما اشرنا اليه . وصلّ اللهم على سيدنا محمد وعلى آله وصحبه اجمعين . 


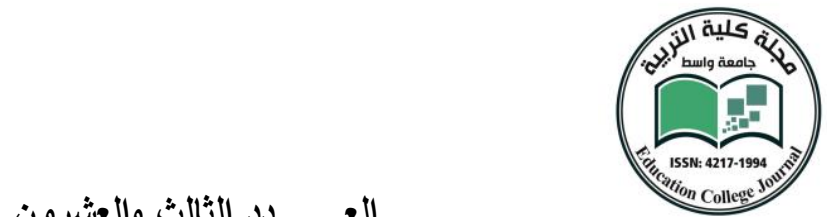

\section{المصادر والمراجع}

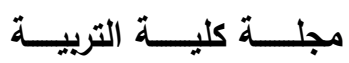

القرآن الكريم •

ا- اتجاهات التفسير في القرن الرابع عشر / للإستاذ الدكتور فهد بن عبد الرحمن بن سليمان الرومي، المملكة

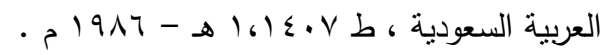

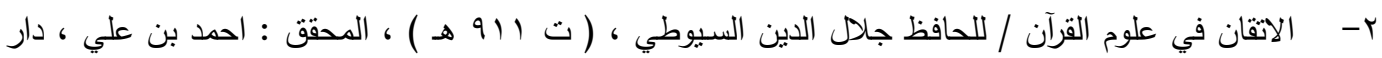

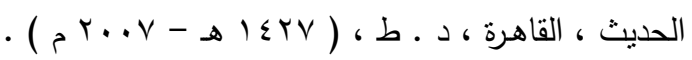

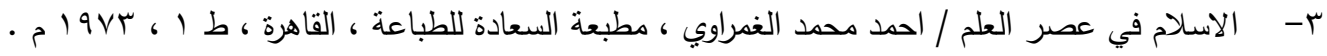

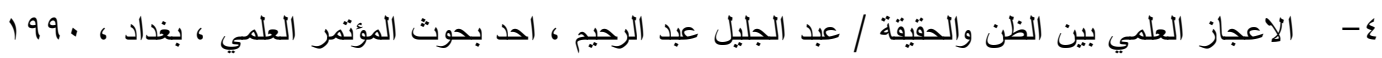

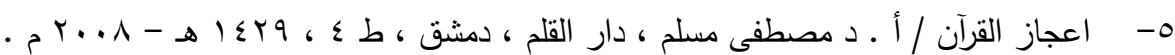
צ- الأعلام : خير الدين بن محمود بن محمد ابن علي الزركلي الدمشقي (ت جوبا (هـ) ، دار العلم للملايين

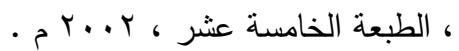
V- بغية الوعاة في طبقات اللغوبين والنحاة : جلال الدين ، عبد الرحمن بن ابي بكر السيوطي (ت II9ه) ، المحقق :محمد ابو الفضل ابراهيم ، المكتبة العصرية ، لبنان - صيدا .

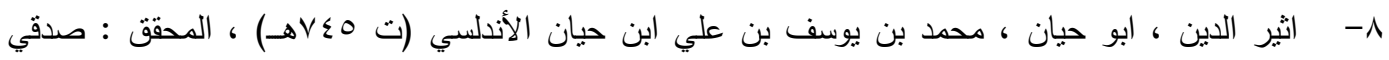

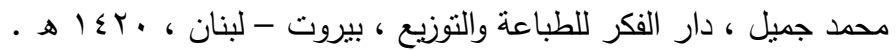

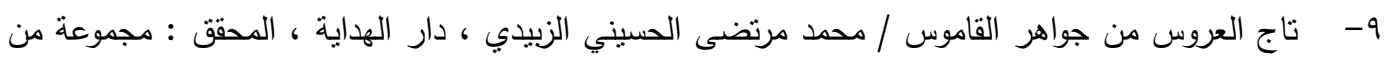

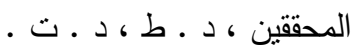
• ا- تأصبل الاعجاز العلمي في القرآن والسنة / الثيخ محمد الأمين ، خلاصة بحث التفسير العلمي بين مجيزيه

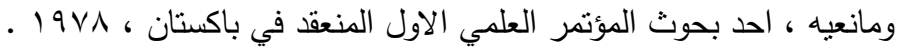
1) - ترتيب القاموس / الفيروز آبادي ، المحقق : احمد طاهر الراوي ، دار المكتبة العربية ، د ـ ط ، د ـ ت . .

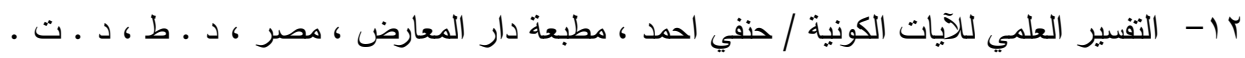
با-- التفسير العلمي للقرآن الكريم / صلاح عبد علي ، رسالة ماجستير ، كلية الثريعة ، قسم الدراسات العليا ، - $19 \mathrm{AV}$

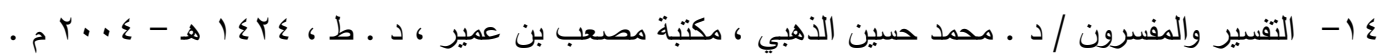


10 - دحض دعوة المشركين ان القرآن من عند النبي (صلى الله عليه وسلم) ، سعود عبد العزيز الخلف ، غراس

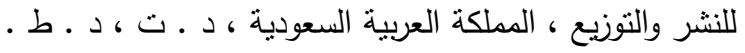

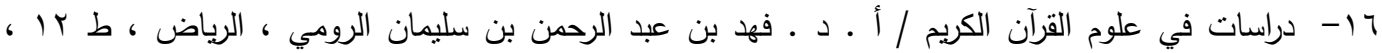
.

Vا-الدرر الكامنة في أعيان المائة الثامنة : لأبن حجر العسقلاني ، المحقق : محمد عبد المعيد ضان ،

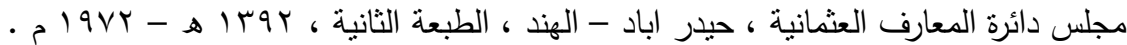

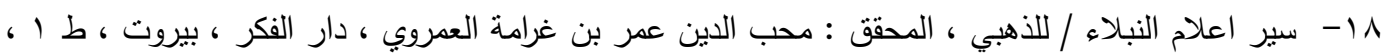
- م199V

9 1 - شبكة الانترنيت موقع ( Google ) الاعجاز العلمي في القرآن الكريم والسنة ، عبد الحميد الزنداني • • ץ- - طبقات المفسرين / لشمس الدين محمد بن علي بن احمد الداودي ، (ت هبوهـ) ، المحقق : علي محمد عمر

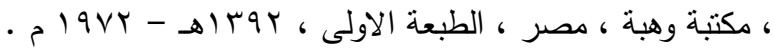
اب- العين للخليل بن احمد الفراهيدي ، دار ومكتبة الهلال ، المحقق : د . مهذي المخزومي ، د ـ ابراهيم

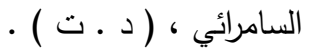

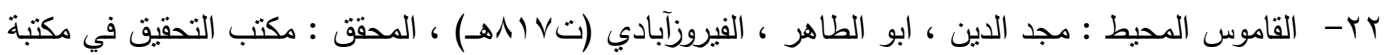

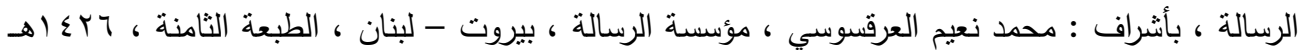
$\cdot 5$ r. O -

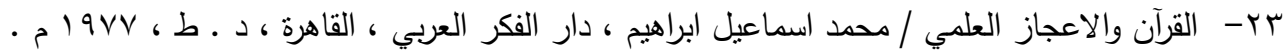

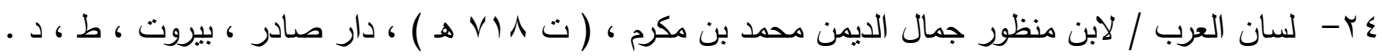

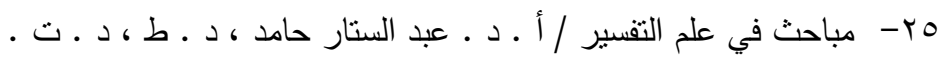

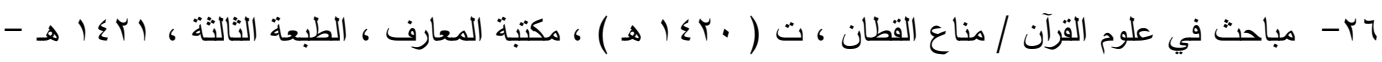
. $r$...

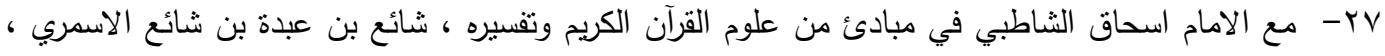

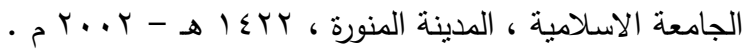

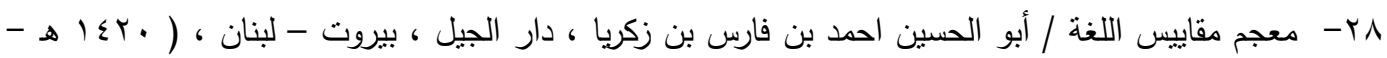

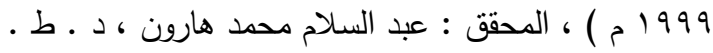




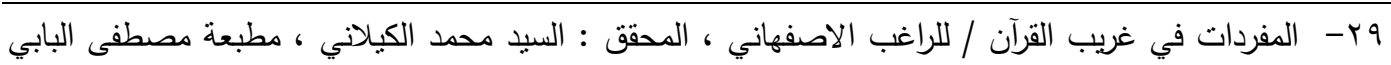

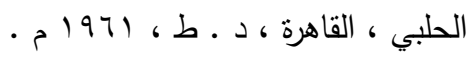

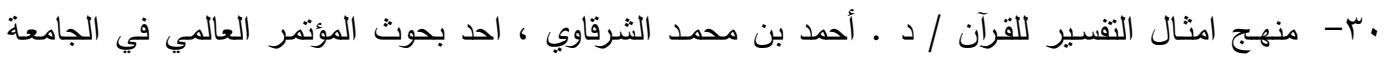

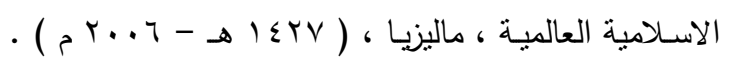

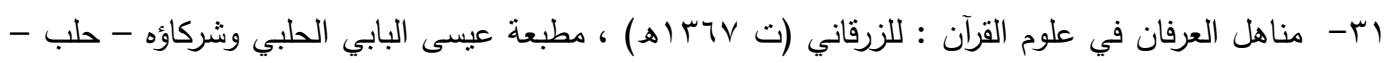

سوريا ، الطبعة الثالثة . 


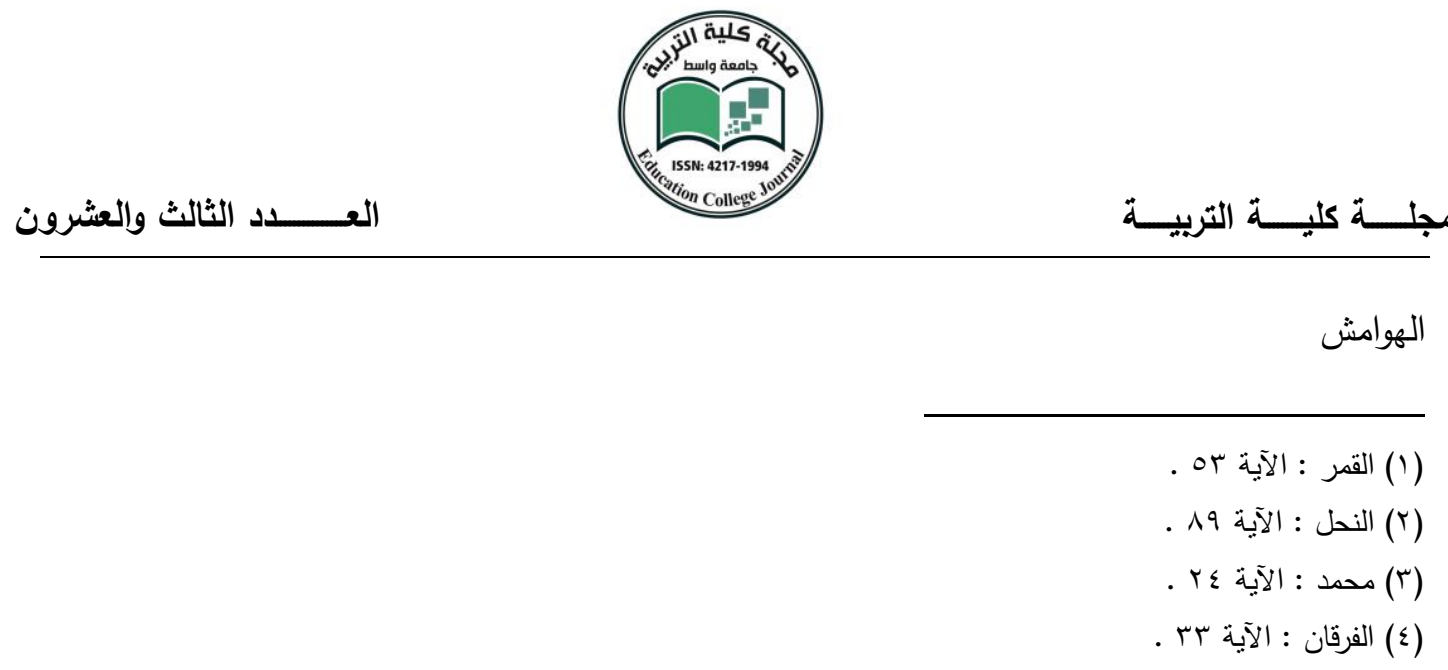

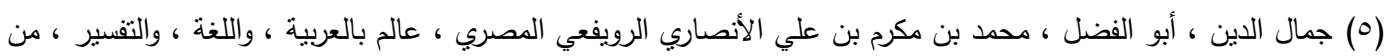

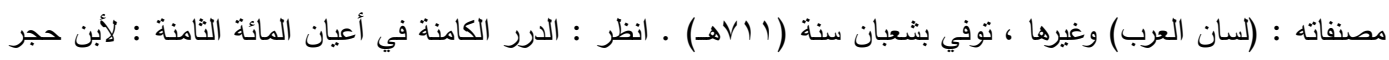

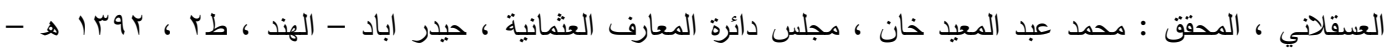

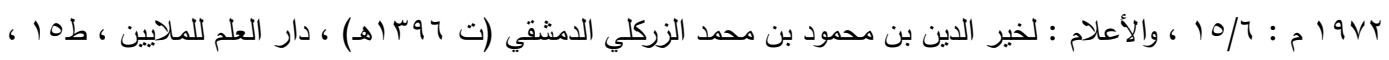

$$
\begin{aligned}
& \text { أيار r.... }
\end{aligned}
$$

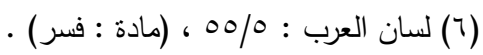

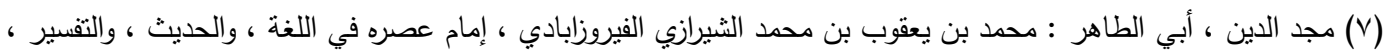

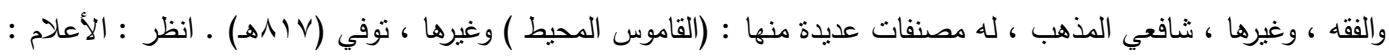
$.1 \leqslant V-1 \leqslant 7 / V$

(^) القاموس المحيط : للفيروزابادي ، المحقق : مكتب المحقق مؤسسة الرسالة ، بأشراف : محمد نعيم العرقسوسي ، مؤسسة

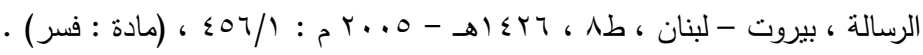

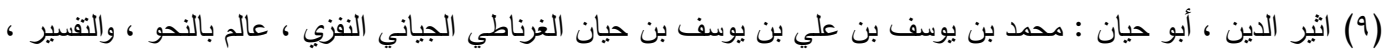

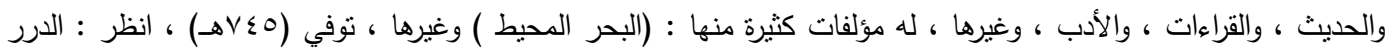
الكامنة :

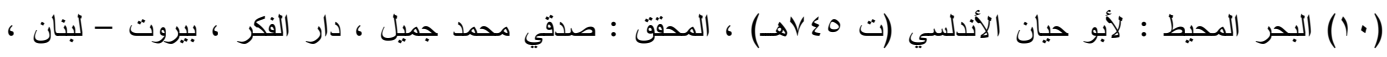
r $r / 1:$ : $1 \leqslant r$.

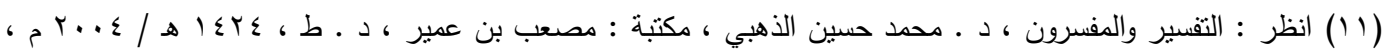

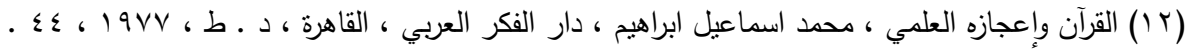

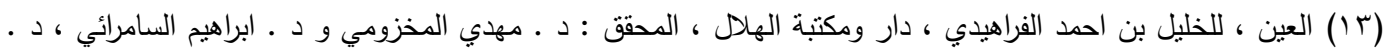

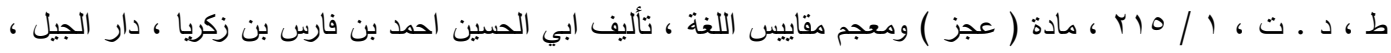

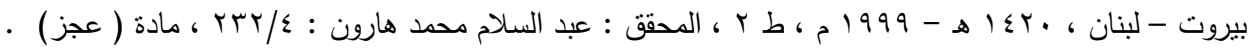




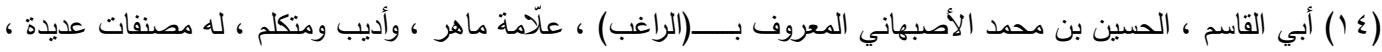

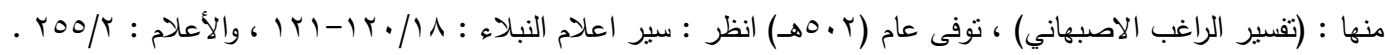

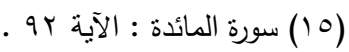

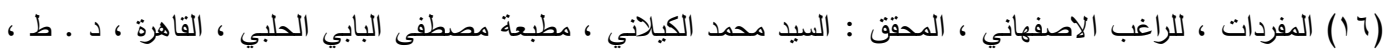

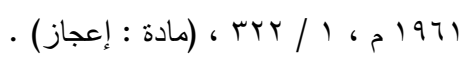

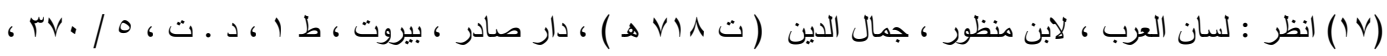

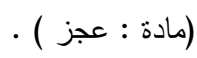

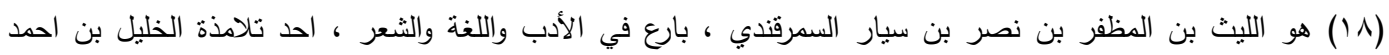

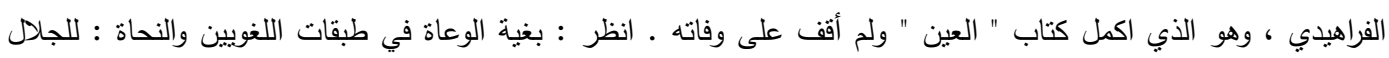

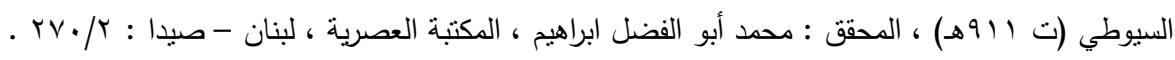

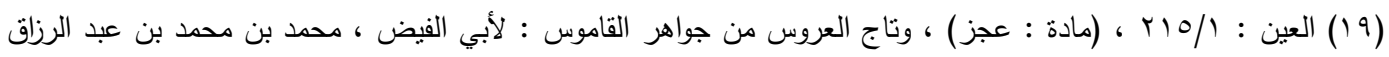

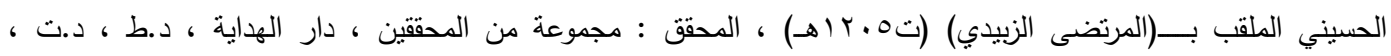
. $r 11 / 10$

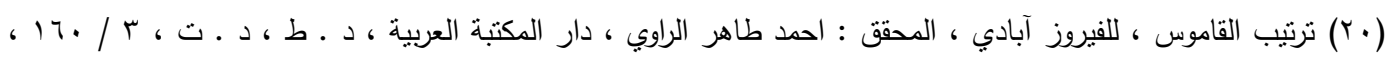

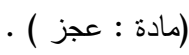

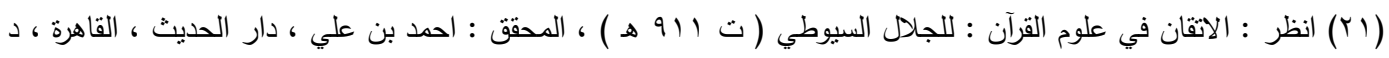

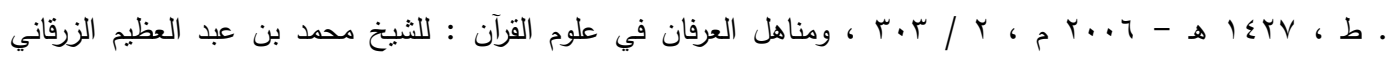

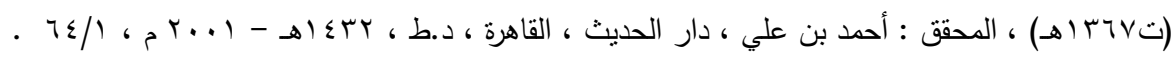

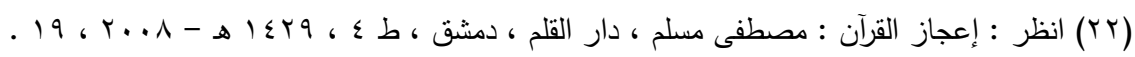

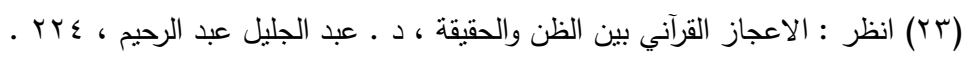

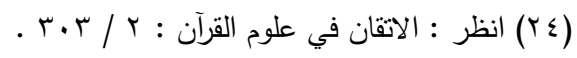

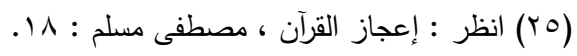
(דץ) اتجاهات التفسير في القرن الرابع عشر ، الاستاذ الدكتور فهد بن عبد الرحمن بن سليمان الرومي ، المملكة العربية

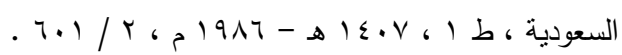

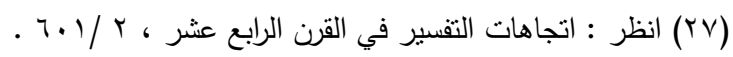

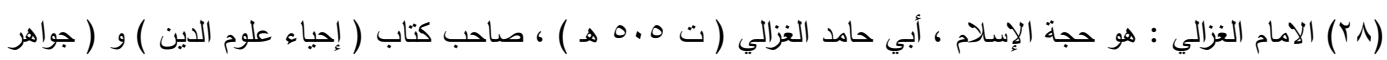

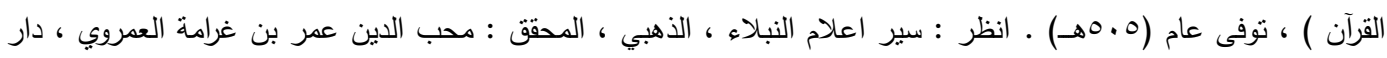

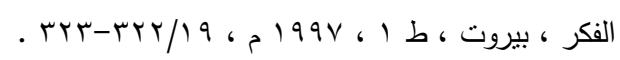

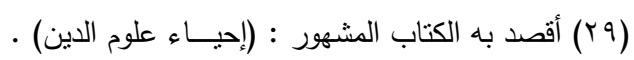


( • الإمام الرازي : هو فخر الدين ، أبو عبد الله ، محمد بن عمر بن الحسين القرشي البكري التيمي الرازي ، المفسر ، المتكلم

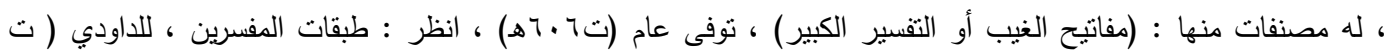

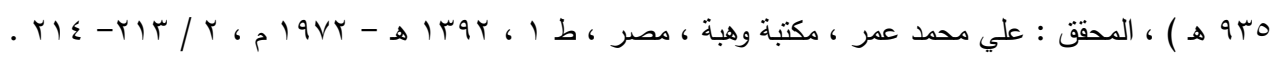

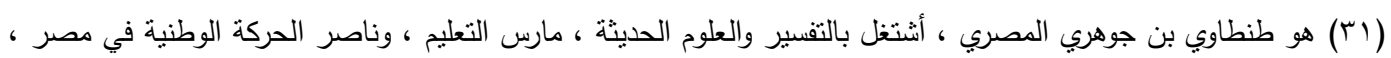

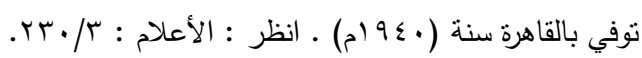

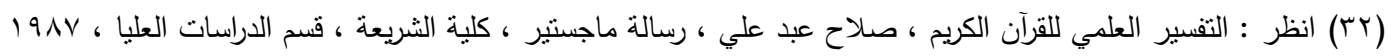

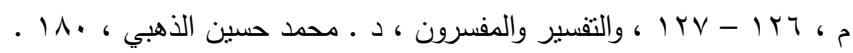

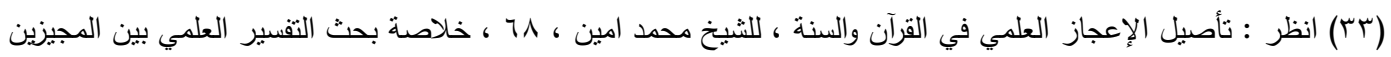

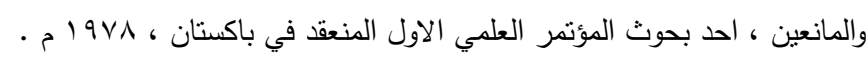

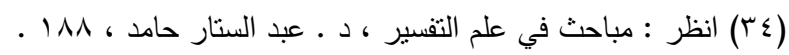

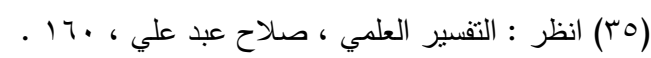

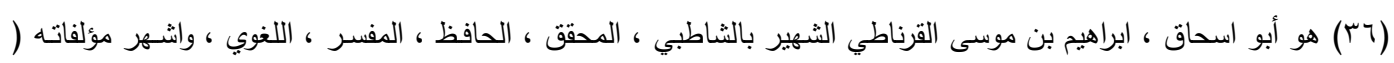

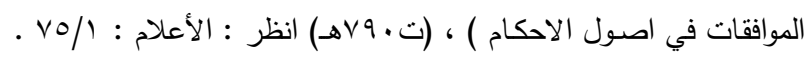

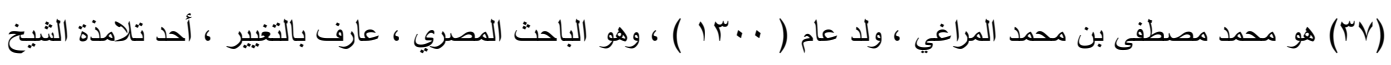

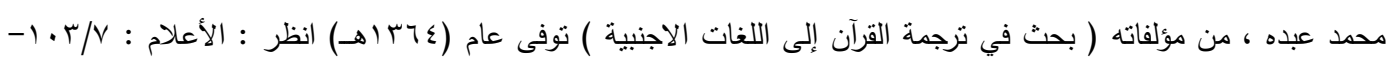

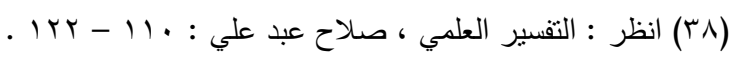

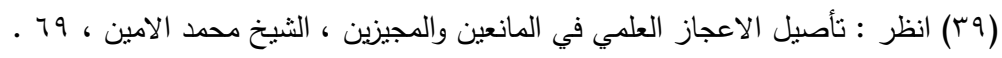

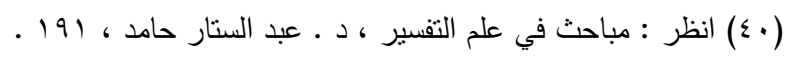

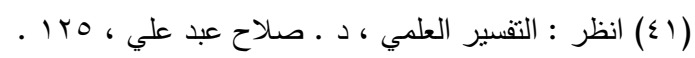

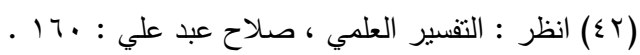

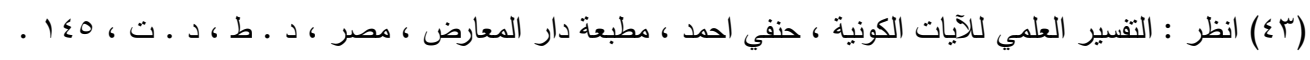

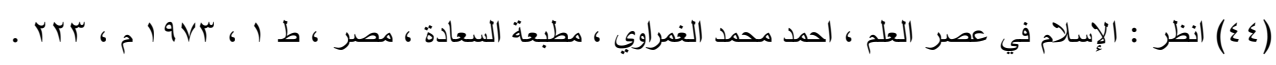

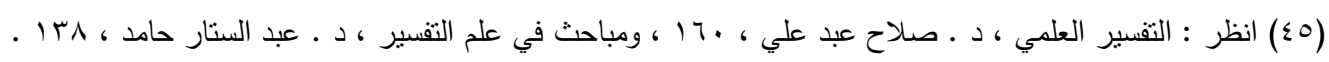

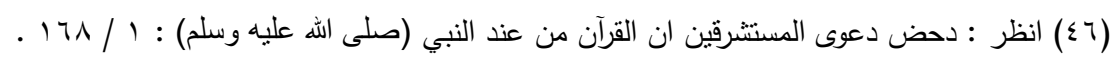

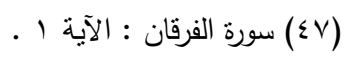

(^) انظر : تأصيل الاعجاز العلمي ، رابطة العالم الإسلامي ، من ابحاث المؤتمر العالمي الاول للاعجاز العلمي في القرآن

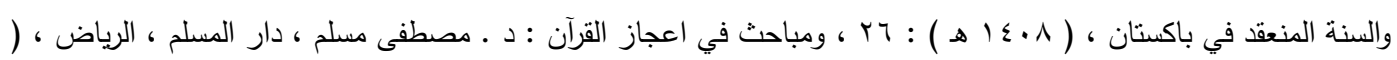

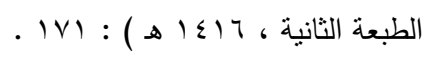

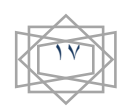




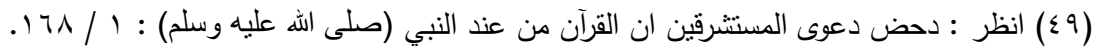

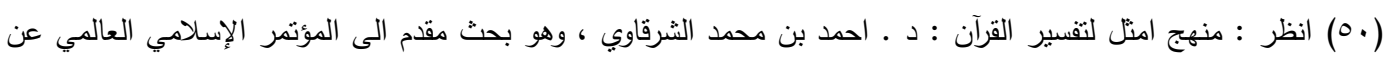

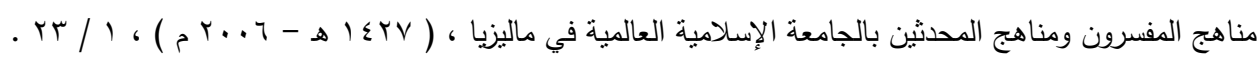

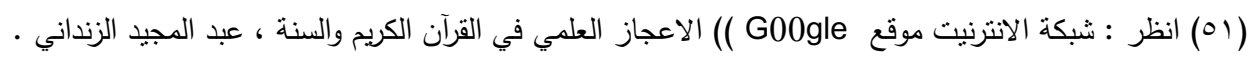

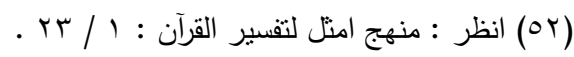

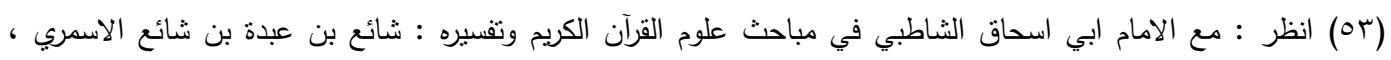

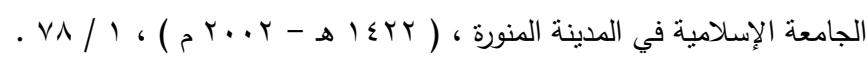

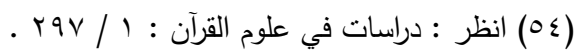

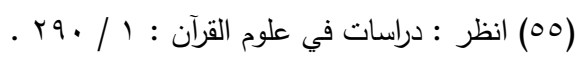

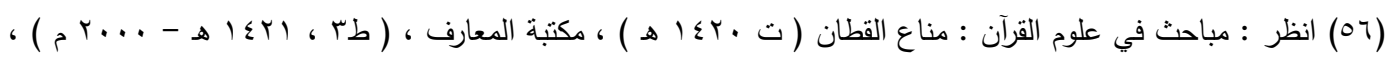
r rVA / I 